\title{
ИЗОБРЕТЕНИЕ (ГОМО)СЕКСУАЛЬНОСТИ. ИСТОРИЧЕСКИЙ, СОЦИАЛЬНЫЙ И КУЛЬТУРНЫЙ АСПЕКТЫ
}

\author{
И.С. АДМИРАЛЬСКАЯ
}

${ }^{a}$ Университет штата Рио-де-Жанейро (EGeS/IMS/UERJ), R. Săо Francisco Xavier, 524, Maracana, Rio de Janeiro - RJ, Cер 20550-900, Бразилия

\section{Резюме}

В настоящем тексте предпринята попытка ознакомить практикующего психолога с историческим, культурным и социальным подходами к рассмотрению сексуальности от появления сексологии как отдельного направления в медицине конца XIX в. до 1980-х гг. Замысел статьи связан с ограниченной применимостью в практике психолога доминирующих дискурсов сексуальности в силу их узости и скудности и необходимостью более широкого понимания предмета, позволяющего выйти за пределы редукционизма и эссенциализма, присущих этим дискурсам. В тексте приводятся основные идеи из ключевых работ, посвященных критическому исследованию феномена сексуальности; для ведения полемики используются «История сексуальности» философа Мишеля Фуко, «Тело и сексуальность» историка Джеффри Уикса и «Размышляя о сексе: заметки о радикальной теории сексуальных политик» антрополога Гейл Рубин, на пересечении взглядов которых появляется понимание сексуальности как исторического, социального и культурного конструкта. Отдельно анализируется произошедший в рамках сексологии сдвиг фокуса внимания с сексуальных практик на личность практикующего и необходимость появления в связи с этим сдвигом фигур «гомосексуала» и «гетеросексуала». По результатам обзора изменений, которые претерпевало понятие сексуальности в социологии, культурологии и антропологии в течение последних полутора веков, автор делает вывод о том, что на каждом этапе своего развития общество выстраивает специфическое отношение к сексуальности в зависимости от текущих задач политики, сложившейся общественной иерархии и отношений власти. На уровне практики это подразумевает необходимость для консультирующего психолога быть готовым критически дистанцироваться от социальных представлений о сексуальности и анализировать влияние этих представлений на процессы формирования и становления конкретной личности, в частности собственной, для того, чтобы не воспроизводить их во время своей работы.

Ключевые слова: сексуальность, практическая психология, консультирование, дискурс, редукционизм, эссенциализм, конструктивизм.

Мы не можем обосновать чувством голода все богатство и сложность кулинарии. Г. Рубин

В работе практикующего психолога сексуальность может стать предметом обсуждения в самых разных контекстах: мы можем иметь 
дело с супружеской парой, «маскирующей» разнообразными конфликтами многолетнюю сексуальную дисфункцию; с ребенком, мастурбирующим в детском саду; с взрослым человеком, который стыдится и ставит под сомнение свои сексуальные практики и фантазии; с подростком, переживающим смятение под натиском происходящих с ним изменений; с человеком, в истории которого есть эпизод сексуального насилия или использования его тела в интересах другого; с пожилым человеком, переживающим угасание влечения и через этот процесс сталкивающимся с темами старения и смерти... Вопросы сексуальности встают перед консультирующим практиком, и в поисках ответа он нередко сталкивается с лакунами в своем образовании, поскольку, кроме психоаналитической теории и представления о психологической составляющей копулятивного акта, ему не на что опереться. Основным источником информации о норме и патологии в сфере сексуальности для большинства специалистов-психологов становится МКБ-10, составленная в виде списка симптомов, но не отвечающая на вопросы «почему?», «как?» и «для чего?», которые встают в рамках конкретной психологической практики. Например, почему одни проявления сексуальности считаются нормальными, а другие - нет? Какие сексуальные практики можно считать «естественными» и что стоит за этим словом? Чем определяется направление сексуального влечения? Может ли оно меняться в течение жизни? Какую роль сексуальность играет в нашем самоопределении?
Если консультирующий практик опирается только на эссенциалистский и биологически-редукционистский подходы к сексуальности подробней речь о них пойдет ниже, он может столкнуться с затруднениями в работе с темами, связанными с сексуальностью. В рамках этих дискурсов сексуальность морализируется, медикализируется и патологизируется, что серьезно ограничивает возможность исследовать вместе с клиентом символические и культурные аспекты процесса переживания и проживания влечения, табу и фантазий... Знакомство с конструктивистскими подходами позволяет занять позицию критического дистанцирования по отношению к патологизирующему дискурсу и открывает возможности для исследования целого пласта социальнодетерминированных установок и паттернов взаимодействия с собой и другими в отношении сексуальности. Кроме этого, специалист получает возможность выстроить с клиентом доверительное пространство, защищенное от вторжения со стороны морали, не вступая при этом в конфликт с собственным отношением к предмету. Конструктивистский подход «выводит» сексуальность из поля влияния морали в пространство ценностей, снижая напряжение в отношении тем, связанных с нею.

Цель данной статьи - проанализировать контекст появления и развития сексологии как науки на рубеже XIX-XX вв. и проследить общественные трансформации отношения к сексуальности на примере ключевых работ, представляющих предмет как продукт культуры. Перед автором стоит задача проанализировать, 
насколько разные подходы к рассмотрению сексуальности применимы к нашей реальности в контексте практики. Обсуждение вопроса происходит на пересечении плоскостей «знание», «общество», «индивид». Автор предлагает читателю критически взглянуть на категории «нормы» и «патологии» в сексуальности и попытаться увидеть за ними культурно-исторический контекст, определяющий то или иное понимание этого вопроса. Текст выстроен с опорой на работы философа Мишеля Фуко, историка Джеффри Уикса и антрополога Гейл Рубин. Последовательно излагаются выводы авторов, изучающих сексуальность, с акцентом на социально-исторические условия и контекст отношений власти и контроля в этой области.

\section{Сексуальность как предмет научного изучения}

Тело, а вслед за ним и сексуальность как проявление телесного можно рассматривать в качестве естественной, природной основы нашего опыта. По телу пролегает граница между личным и общественным, поскольку все наше поведение имеет социально-культурную основу и сексуальность, каким бы личным делом она ни казалась, проявляется в заданных обществом рамках. Долгое время в истории человечества вопросами сексуальности занималась религия, но к концу XIX в. сложились все предпосылки для кардинальной трансформации корпуса знаний, связанных с влечением, сексуальными практиками и нормами поведения (Weeks, 1999).

В конце XIX в. сексуальностью начинает заниматься медицина, и она становится предметом научного изучения. Подразделение медицины, получившее название «сексология», претендует на выработку норм и правил в той области, которая прежде регулировалась церковью. Родоначальниками новой отрасли медицины становятся Рихард фон КрафтЭбинг и Генри Хэвлок Эллис. В 1886 г. выходит книга Крафт-Эбинга (1996) под названием «Половая психопатия», в которой он описывает широкий репертуар сексуальных практик, некоторым из них он вынужден давать названия, поскольку они впервые фиксируются в специальной литературе. В 1897 г. выходит первый том семитомной энциклопедии «Исследования психологии пола» Эллиса (Ellis, 1915). Обе работы вызывают шквал протестов викторианской публики, появляются обвинения авторов в стремлении шокировать общественность путем обнародования непристойности под видом науки. Однако работы активно переиздаются, что позволяет сделать вывод о том, что в конце XIX в. общество входит в новый виток своего развития: табу викторианской эпохи снято, а сексуальность переходит из поля влияния морали, установленной церковью, на территорию науки.

Хотя оба ученых - врачи, их подход к вопросам, связанным с сексуальностью, сильно различается. Материалом для исследований Крафт-Эбинга становятся пациенты клиник для умалишенных и заключенные, обвиняемые в непристойных действиях, а Эллис описывает свои частные наблюдения, касающиеся эпизодов из жизни «обычных» людей. Крафт-Эбинг подходит к теме сексуальных практик с клинической 
точки зрения, исследуя границы между нормой и патологией, а Эллис выступает в роли публициста - описывает и анализирует многообразие и вариативность сексуальных проявлений в контексте культуры, стадий развития общества, влияния социума на личность и др. Авторов объединяет ви́дение сексуальности как природного феномена, роднящего человека с животным миром и являющегося частью врожденного механизма, связанного с размножением.

Отдельно стоит сказать об отношении «отцов сексологии» к гомосексуальности и проявлению либидо в незрелом возрасте, чтобы обозначить стартовую точку, в которой (гомо)сексуальность входит в поле зрения науки. Для Крафт-Эбинга она является признаком «церебральной аномалии» - «извращенного полового чувства», связанного с тем, что взрослый мужчина испытывает к другому мужчине «чисто женское влечение», а женщина испытывает к другой женщине «мужское» влечение. Эллис рассматривает гомосексуальность как инверсию влечения и предпринимает попытку этнографического анализа этого феномена как одного из элементов традиционной культуры, описывая обычаи «отсталых» народов - от Индии до Новой Гвинеи.

Возвращаясь к сексологии, очертим задачи, которые стояли перед этой молодой отраслью медицины.
С одной стороны, она описывала и предписывала адекватное сексуальное поведение для женщины и мужчины, связывая его с «биологической» ${ }^{1}$ базой, а с другой стороны определяла рамки нормы и описывала все, что выходило за них, в качестве патологии. Через понятие «сексуальные перверсии» вводятся границы между «естественным» и «неестественным», и это становится актуальным именно в текущий момент конца XIX в. Идея об общественном контроле за сексуальностью с целью создания благополучного «общественного тела» (совокупности тел граждан) будет позже развита французским философом Мишелем Фуко, но уже сейчас в работе Крафт-Эббинга она сформулирована довольно четко. В этом контексте важно подробнее остановиться на том, как представление о «природных» основах сексуальности становится основанием для построения контроля над «общественным телом».

Постулаты о норме и патологии в сексологии конца XIX в. сформировали основания общественной политики в области сексуальности. Привязка к «естественности» и «природному инстинкту» в логике организации и построения знания о человеке здесь кажется очень важной, поскольку она позволяет выстроить цепочку от определения того, что является натуральным и природным, к закреплению социальных иерархий и неравенства.

\footnotetext{
${ }^{1}$ Мы берем слово «биологической» в кавычки, поскольку выбрать из всего многообразия и богатства проявлений что-то одно и называть это нормой - для женщины и мужчины в единственном числе - представляется искусственным конструированием понятия «биологическая норма».
} 
По мнению бразильского антрополога Серджио Каррара (Carrara, 2015), в развернутом виде эта цепочка выглядит так: выбор из многообразия проявлений одной конкретной формы какого-то свойства - закрепление его как принадлежащего телу - якорение этого явления как натурального, естественного, связанного с природой - определение его как неизменяющегося, устойчивого, не поддающегося влиянию - придание ему негативного значения выстраивание на основе этого значения иерархии и неравенства. Сама идея о существовании полового диморфизма рассматривалась как природная основа для формулировки норм поведения и предписаний для каждого из полов: от сравнения объемов черепа и ширины таза - к полемике о том, нужен ли женщине доступ к образованию. Сейчас уже трудно поверить, но в определенный момент в истории медицины телесные особенности мужчин и женщин связывались с траекторией их социализации и той ролью в обществе, которую им было предписано исполнять в соответствии с «природой» каждого из полов (Rohden, 2001). Сексуальность была одним из контекстов, обосновывающим именно такие нормы поведения и распределение ролей в обществе.

\section{Мишель Фуко: концепция сексуальности как исторического диспозитива}

На современное представление о сексуальности в науках о человеке заметное влияние оказали работы французского философа и историка Мишеля Фуко. Он рассматривает сексуальность как один из социальных конструктов, исторических «устройств», изобретенных в западном обществе XIX в. Эти конструкты - «диспозитивы» в терминах Фуко - появляются на определенном этапе общественной истории как совокупность знаний, практик, норм и социальных институтов, так или иначе организующих отношения между людьми и их представления о мире. В первом томе работы «История сексуальности» (Foucault, 1988) Фуко выступает в роли историка, описывая нововведение середины XIX в. представление о влечении как о телесной энергии природного происхождения. Эта концепция является составной частью совокупности знаний, дискурсов и суждений о теле и удовольствии вообще, которое противопоставляется предыдущему регулирующему, объясняющему и организующему интимные отношения принципу, который Фуко называет «брачным устройством». Задачей брачного устройства является регуляция матримониальных отношений, правил наследования фамилии и собственности, производство благ и передачи статуса посредством социальных норм, обычаев и церковных законов. Переход от одного конструкта к другому - от «брачного устройства» к «сексуальности» связан с расцветом естественно-научного подхода и с изучением и «обнаружением» телесной природы человека, а также места удовольствия в реальности наших тел. В новом подходе, оперирующем наблюдениями, а не правилами морали, сексуальные практики «выходят» за пределы брачной территории; они оказываются замечены, описаны и наталкивают 
общество на закономерные вопросы. Сексуальность для Фуко - это то, что тесно связано с властью, с процессами организации общества, с управлением знанием. Он описывает четыре стратегических маршрута, которые разворачиваются властью в отношении сексуальности в течение XVIII-XIX вв.: определение и научное обоснование подчиненного места женщины, крестовый поход против детской мастурбации в школах и семьях, патологизация и криминализация половых перверсий, разработка общественного контроля над рождаемостью через нормы морали и стыд: «В озабоченности сексом, которая возрастает на протяжении всего XIX века, вырисовываются четыре фигуры - четыре привилегированных объекта знания, четыре мишени и точки закрепления для разного рода демаршей знания: истеричная женщина, мастурбирующий ребенок, мальтузианская пара, извращенный взрослый, - фигуры, каждая из которых соответствует одной из перечисленных стратегий, которые - каждая по-своему - пронизали и использовали секс детей, женщин и мужчин» (Фуко, 1996, c. 206).

Согласно Фуко, основным мотивом «общественного заказа» на изучение сексуального поведения человека становится контроль за его поведением, здоровьем и посредством этого - контроль за популяцией в целом. В этом смысле секс перестает быть чем-то личным и переходит в сферу общественных интересов, став предметом научного изучения, контроля и влияния. Сексуальное влечение понимается как нечто природное и естественное, влияющее на формирование личности, но сексуальные практики как способы реализации влечения описываются и оцениваются как «естественные» или «неестественные» внутри научного сексологического дискурса. В результате этой каталогизации среди прочих появляются такие стигматизированные персонажи, как «фетишист» и «гомосексуал». Фокус внимания смещается с эротических практик, где он находился в рамках религиозного дискурса (оперирующего категориями греха и покаяния), на самого индивида: в поле влияния медицины эротические предпочтения человека становятся маркером патологической личности, а разнообразные практики, воспринимавшиеся до этого как поведенческие акты, категоризируются как отклонения и дефекты, имеющие отношение не к поведению, а к структуре личности, особенностям индивида. Они становятся предметом наблюдения и контроля со стороны таких социальных институтов, как медицина и юриспруденция. Другими словами, то, что было элементом обыденной частной жизни, «захватывается» и медикализируется, патологизируется и криминализируется. Личное становится политическим, хотя и продолжает называться «естественным», «природным», «натуральным».

\section{Джеффри Уикс: историческое значение сексуальности}

Английский историк Джеффри Уикс рассматривает появление концепции сексуального влечения как природного инстинкта, требующего удовлетворения, как действие 
постдарвиновского стремления объяснить все феномены человеческого поведения в биологических терминах, присущего концу XIX в. Он пишет: «Хотя сейчас мы склонны объяснять те же самые феномены действием гормонов и генов, представление о биологических “корнях" не сдает позиции, и именно в сфере сексуальности проявляет свою устойчивость» (Weeks, 1999, p. 39). Анализируя определение сексуального инстинкта, данное Крафт-Эбингом, Уикс подчеркивает два качества, приписываемых влечению в работе последнего, - вулканическую взрывоопасность и телесную природу. В тексте Эллиса сексуальность описывается как сила, формирующая человека, пронизывающая насквозь всю его личностную конституцию вплоть до того, что «мужчина таков, каков его секс». В опоре на этот текст Уикс приходит к обнаружению третьей особенности, связанной с концепцией сексуальности, - она существует лишь в мире мужчин, описывается «мужским» языком и связана с маскулинностью - активным, проникающим, завоевывающим подходом. Другими словами, Джеффри Уикс в концепции сексуальности конца XIX в. находит отражение культурных явлений и конструкций, присущих этой эпохе: постдарвинизма, редукционизма и патриархата. В этом свете ясно видно, что знание само по себе конструируется в рамках того культурного контекста, которому оно принадлежит.

Уикс выделяет следующие характерные особенности концепции «сексуальности», показывающие, как глубоко она встроена в культуру в качестве одной из ее составляющих:
• она призвана прояснить и закрепить широкий круг представлений, связанных с различиями между мужчинами и женщинами в том, что касается их интеллектуальных, физических (в том числе репродуктивных) возможностей и социального статуса;

- она содержит в себе ожидания в отношении того, что считается «правильным» или «неправильным», желательным и нежелательным в поведении человека;

- она выстраивает связь между индивидуальными особенностями людей (их идентичностью, чувственностью и интимными переживаниями) и пространством социального, культурного и политического, например, в том, что касается организации семьи и признания отцовства, разделения профессий на «мужские» и «женские», морального кодекса и законов.

Исследуя термины «гомосексуальность» и «гетеросексуальность», Уикс обнаруживает их сравнительно недавнее происхождение - они впервые появляются в 1869 г. в работе австро-венгерского автора Карла Кертбени. По мнению Уикса, введение этих терминов знаменует собой важный этап в разработке концепции сексуальности, поскольку фиксирует социальную норму, относящуюся к интимной стороне жизни человека. В тексте Кертбени термин «гомосексуал» играет вспомогательную роль в содержательном определении термина «гетеросексуал»: для того чтобы обозначить границы понятия «гетеросексуал», вводится представление о гомосексуальном человеке, испытывающем эмоциональную привязанность и влечение к представителям 
своего пола. Контекст, в котором появляются эти термины, определяет их социальную значимость и «необходимость»: речь идет о судебной реформе в Германии, в ходе которой, в частности, планируется отменить ответственность за содомию. Как считает Уикс, формулировка этих терминов является маркером перехода от рассмотрения гомосексуальности как одной из сексуальных практик к квалификации ее как устойчивой характеристики индивида.

Продолжая логику социальноисторического конструирования сексуальности, бразильский антрополог британского происхождения Питер Фрай (Fry, 1982) исследует изменения представлений о гомосексуальности в культуре Бразилии. Он сравнивает два десятилетия, разделенные движением за права женщин, и два социальных класса (средний класс в столице и рабочий класс на периферии). Исследование показывает, как сильно меняются понятийные схемы в зависимости от социального контекста. Маркером для построения идентичности до развития движения за права женщин является гендерная роль (фемининный мужчина и маскулинный мужчина в гомосексуальной паре). Буквально через десять лет базой для сексуальной идентификации уже является не гендерная роль, а сексуальная ориентация (снимается табу на отношения между двумя одинаково маскулинными мужчинами и прежняя схема контакта между «активным» маскулинным мужчиной и «пассивным» феминизированным мужчиной трансформируется в схему контакта двух гомосексуальных мужчин). То, что считается правильным, естествен- ным сейчас, спустя краткий промежуток времени может трансформироваться во что-то другое. Перемещая фокус внимания с деталей конкретной эпохи на изменения концепции сексуальности в истории, мы можем заметить, что содержание этой концепции довольно точно отражает особенности культуры, которая ею оперирует. Представления о сексуальном - это один из культурных маркеров, высвечивающих отношения власти, доминирования, общего и частного.

\section{Гейл Рубин: концепция сексуальной стратификации}

Американский антрополог Гейл Рубин рассматривает современный ей подход к сексуальности (1980-е гг.) как проявление эссенциализма попытки привязать сексуальность к биологическим характеристикам человеческого тела, не беря в расчет культурные, исторические и социальные аспекты. Рубин пишет: «Человеческая сексуальность не может рассматриваться исключительно в биологических терминах. Человеческие организмы с человеческими умами требуют человеческих культур, поскольку ни одно из исследований тела или его частей не может дать объяснение природе и разнообразию человеческих социальных систем. Сексуальность - это продукт культуры, так же как диеты, транспортные средства, нормы этикета и многое другое...» (Rubin, 1998, р. 106.)

C опорой на внушительную библиографическую и документальную базу к своей работе «Thinking sex» (1984, 1998, доп. изд.) Гейл Рубин 
пытается определить и описать идеологические концепции, которые повлияли на восприятие сексуального в современном западном мире. Она приходит к следующим заключениям:

- секс воспринимается как нечто исключительно опасное и разрушительное;

- проявления сексуальности должны быть приведены в соответствие с некой общей нормой;

- любое отклонение от этого образца видится как отрицательное проявление, хотя на практике небольшие вариации не угрожают общественному порядку;

- сексуальные акты имеют разную ценность и могут быть выстроены в иерархическом порядке.

Описанные автором закономерности являются логическим продолжением работ Крафт-Эбинга и Эллиса, как если бы за век своего существования сексология набрала внушительный фактический материал, но социальная «изнанка» и принципы использования этой науки в целях власти остались бы теми же, что и в конце XIX в.

Согласно Рубин, идея о том, что секс греховен и может практиковаться только в браке и только с целью зачатия детей без акцента на наслаждении, давно «открепилась» от христианской традиции и существует в обществе сама по себе. Любое эротическое поведение, исполняемое сознательно, квалифицируется как неприемлемое. Исключениями, реабилитирующими секс, являются брак, намерение зачать ребенка и любовь. Другие варианты - например, интерес, исследование, потребность в удовольствии - не могут считаться моральными «основаниями» для сексуальной практики. Иерархизация сексуальных актов производится посредством установления в социуме разделительной линии между «плохим» и «хорошим» сексом. Эта воображаемая линия защищается с такой силой, как будто ее однократное нарушение неминуемо приведет к ужасным последствиям.

Рубин формулирует концепцию сексуальной стратификации - процесса закрепления определенной ценности за каждым из вариантов сексуального акта. Эта стратификация прямо участвует в процессе формирования социального неравенства: определяет и фиксирует более высокое место в иерархической структуре общества для тех, чья сексуальная практика квалифицируется как «правильная», и менее высокое для тех, чья сексуальная практика признается «плохой». Сексуальные практики становятся одним из маркеров неравенства наравне с расой, этносом, полом, классом. Нормы в сфере сексуального превращаются в средство подавления и контроля.

По результатам обзора изменений, которые претерпевало понятие сексуальности в философии, социологии, культурологии, медицине и антропологии в течение последних полутора веков, можно сделать несколько выводов:

- за сексуальностью, которая устойчиво представляется в натурализующем дискурсе как нечто природное, естественное, связанное с размножением, довольно трудно найти телесную основу, поскольку она является культурным продуктом и «инсталлируется» в процессе социализации; 
- на каждом этапе своего развития общество выстраивает специфическое отношение к сексуальности в зависимости от текущих задач политики, сложившейся общественной иерархии и отношений власти;

- в разные временны́е периоды одни и те же сексуальные практики могут переходить из категорий «нормальных» и «одобряемых» в категории «противоестественных» и «порицаемых»;

- система общественного оценивания, подразделяющая сексуальные практики на «плохие» и «хорошие», особенно остро проявляет себя в те исторические периоды, когда обостряется напряжение между консервативным и либеральным течениями в обществе;

- отношение к сексуальности может быть чутким «флюгером» изменений в обществе, что ставит перед консультирующим практиком задачу на постоянное отслеживание своей позиции в отношении вопроса во избежание попадания под влия- ние текущей установки власти в отношении «общественного тела»;

- и практикующий психолог, и обратившийся к нему человек являются членами общества и могут транслировать общественные установки к сексуальности, но для консультирующего практика важно уметь осуществлять критическое дистанцирование от этих установок для того, чтобы исследовать и подвергать сомнению те убеждения, которые лежат в основе отношения человека к его сексуальности.

На операциональном уровне это может выглядеть как исследование того, как человек обходится со своей сексуальностью, проживает и переживает ее. Проясняющие вопросы, помогающие обнаружить, в какой мере сексуальность принадлежит ему, а в какой - обществу, могут быть ценной рабочей тактикой. Для этого необходимо, чтобы сам психолог был готов подвергать сомнению текущие версии «нормы» и «патологии» в корпусе знаний, относящихся к сексуальности.

\section{Литература}

Крафт-Эбинг, Р. (1996). Половая психопатия. М.: Республика.

Фуко, М. (1996). Воля к истине: по ту сторону знания, власти и сексуальности: Работы разных лет. М.: Касталь.

Carrara, S. (2010). Curso de especialização em Gênero e Sexualidade. Rio de Janeiro/Brasília, DF: SEPESC/Especial de Políticas para as Mulheres.

Ellis, H. (1915). Studies in the psychology of sex (3rd ed.). Philadelphia, PA: F.A. Davis Company Publishers. Retrieved from https://archive.org/stream/cu31924013996958/cu31924013996958_djvu.txt Foucault, M. (1988) História da sexualidade I. A vontade de saber. Rio de Janeiro: Edições Graal. Fry, P. (1982). Para Ingles ver: Identidade e politica na cultura Brasileira. Rio de Janeiro: Zahar. Rohden, F. (2001). A ciência da diferença: Sexo e gênero na medicina da mulher. Rio de Janeiro: Fiocruz. Rubin, G. (1998). Thinking sex: notes for a radical theory of the politics of sexuality. In P. M. Nardi \& B. E. Schneider (Eds.), Social perspectives in lesbian and gay studies: A reader (pp. 100 -133). New York: Routledge. 
Weeks, J. (1999). O corpo e a sexualidade. In L. G. Louro (org.), O corpo educado: pedagogias da sexualidade (pp. 35-82). Belo Horizonte: Autęntica.

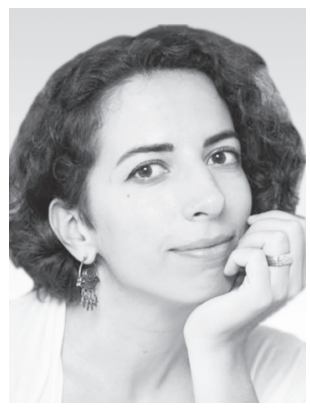

Адмиральская Инга Сергеевна - независимый исследователь; студент курса специализации в области гендера и сексуальности, Университет штата Рио-де-Жанейро, Бразилия (EGeS/IMS/UERJ), Ph.D.

Сфера научных интересов: изучение гендерной неконформности, сексуальной и гендерной идентичности.

Контакты: admiralskaya@gmail.com 


\title{
The Invention of (Homo)sexuality. Historical, Social and Cultural Aspects
}

\author{
Inga S. Admiralskaya ${ }^{a}$
}

${ }^{a}$ State University of Rio de Janeiro (EGeS/CLAM/UERJ), R. Săo Francisco Xavier, 524, Maracana, Rio de Janeiro - RJ, Cep 20550-900, Brazil

\begin{abstract}
The present text is an attempt to introduce the practitioner psychologist to historical, cultural and social approaches to sexuality from the emergence of sexology as a distinct school of medicine in the end of the XIX century till the 80ies of the XX century. The message of this article is induced by the limited applicability in psychological practice of the dominant discourses of sexuality in virtue of their parochialism and poverty, and the necessity of a more broad understanding of the subject that will allow to step out reductionism and essentialism, which are inherent in those discourses. The article cites the main ideas of the key works, dedicated to critical studies of the sexuality phenomenon: History of Sexuality by the philosopher Michel Foucault, Body and Sexuality by the historian Jeffrey Weeks and Thinking Sex: Notes for a Radical Theory of the Politics of Sexuality by the anthropologist Gayle Rubin are used for polemics; at the intersection of their views appears the understanding of sexuality as a historical, social and cultural construct. Aside is analyzed the shift in the framework of sexology of the focus of attention from sexual practices to personality of the practicing person, and the necessity of the appearance of the figures of "homosexual" and "heterosexual" due to this shift. In accordance with the review of the changes of the notion of sexuality in sociology, culturology and anthropology during the last one and a half centuries, the author comes to the conclusion that on each stage of its development the society builds a specific attitude towards sexuality, depending on current tasks of politics, established societal hierarchy and relations of authority. On the level of practice it implies the necessity for a counseling psychologist to be ready to critically distance him/ herself from social notions of sexuality and to analyze influence of these notions on the processes of formation and development of a particular personality, including his/her own, in order not to replicate them in the process of his/her work.
\end{abstract}

Keywords: sexuality, practical psychology, counselling, discourse, reductionism, essentialism, constructionism.

\section{References}

Carrara, S. (2010). Curso de especialização em Gênero e Sexualidade. Rio de Janeiro/Brasília, DF: SEPESC/Especial de Políticas para as Mulheres.

Ellis, H. (1915). Studies in the psychology of sex (3rd ed.). Philadelphia, PA: F.A. Davis Company Publishers. Retrieved from https://archive.org/stream/cu31924013996958/cu31924013996958_djvu.txt Foucault, M. (1988) História da sexualidade I. A vontade de saber. Rio de Janeiro: Edições Graal.

Foucault, M. (1996). Volya $k$ istine: po tu storonu znaniya, vlasti i seksual'nosti: Raboty raznykh let [The will to truth: beyond knowledge, power and sexuality: Works from different years]. Moscow: Kastal'. 
Fry, P. (1982). Para Ingles ver: Identidade e politica na cultura Brasileira. Rio de Janeiro: Zahar.

Krafft-Ebing, R. (1996). Polovaya psikhopatiya [Psychopathia sexualis]. Moscow: Respublika. (Transl. of: von Krafft-Ebing, R. (1907). Psychopathia sexualis (13. vermehrte Ausgabe). Stuttgart: Ferdinand Enke. (in German).)

Rohden, F. (2001). A ciência da diferença: Sexo e gênero na medicina da mulher. Rio de Janeiro: Fiocruz. Rubin, G. (1998). Thinking sex: notes for a radical theory of the politics of sexuality. In P. M. Nardi \& B. E. Schneider (Eds.), Social perspectives in lesbian and gay studies: A reader (pp. 100 -133). New York: Routledge.

Weeks, J. (1999). O corpo e a sexualidade. In L. G. Louro (org.), O corpo educado:pedagogias da sexualidade (pp. 35-82). Belo Horizonte: Autêntica.

Inga S. Admiralskaya - independent researcher, student of postgraduate specialization course «Specialization in gender e sexuality», State University of Rio de Janeiro (EGeS/CLAM/UERJ), Ph.D.

E-mail: admiralskaya@gmail.com 